\title{
Significance of poor performance status after resection of colorectal liver metastases
}

\author{
Peter Strandberg Holka', Sam Eriksson ${ }^{1}$, Jakob Eberhard ${ }^{2}$, Magnus Bergenfeldt ${ }^{1}$, Gert Lindell ${ }^{1}$ \\ and Christian Sturesson ${ }^{1,3^{*}}$ (D)
}

\begin{abstract}
Background: Performance status (PS) is known as one of the strongest prognostic factors for survival in metastatic colorectal cancer patients. The aim of the present study was to analyze factors associated with poor PS assessed after resection for colorectal liver metastases and the impact on survival.

Methods: All patients undergoing curative resection for colorectal liver metastases between 2010 and 2015 in a single center were reviewed retrospectively.

Results: A total of 284 patients were included, out of whom 74 patients (26\%) presented with a postoperative PS WHO $>2$ precluding administration of adjuvant chemotherapy. These patients had a shorter recurrence-free survival $(P=0.002)$ and shorter overall survival $(P<0.001)$. Multivariable analysis showed that patients with $P S>2$ after surgery had higher preoperative ASA score, had a higher frequency of major complications after surgery, and had more frequently synchronous liver and lung metastases. PS was found to be the strongest independent factor predicting survival (hazard ratio 0.45). When patients with postoperative PS $>2$ developed recurrent disease (54 of 74), $43(80 \%)$ received tumor specific treatment.

Conclusions: Patients with postoperative PS $>2$ who did not receive adjuvant chemotherapy had decreased recurrence-free and overall survival after liver resection for colorectal liver metastases. After recurrence, a large majority of these patients had had improvement in PS allowing for administration of tumor specific treatment.
\end{abstract}

Keywords: Colorectal neoplasms, Hepatectomy

\section{Background}

Colorectal cancer (CRC) liver metastatic disease is a significant clinical problem. Up to $25 \%$ of patients with colorectal cancer are diagnosed with synchronous liver metastases and a similar number develop metachronous metastases [1]. When possible, surgical resection is the treatment of choice $[1,2]$. The 5-year survival rates after resection range from 15 to $74 \%[3,4]$, the wide distribution mainly due to differences in patient selection, a development over time with improved chemotherapeutic

\footnotetext{
* Correspondence: christian.sturesson@med.lu.se

'Department of Clinical Sciences Lund, Surgery, Skane University Hospital, Lund University, Lund, Sweden

${ }^{3}$ Department of Surgery, Skåne University Hospital, S-221 85 Lund, Sweden Full list of author information is available at the end of the article
}

and biological agents, improved surgical techniques and a change in multimodality approach [5].

However, about two thirds of the patients develop disease recurrence within 2 years after resection [6]. Adjuvant chemotherapy aims to treat micro-metastatic disease to reduce the risk of relapse [7]. The strategy of perioperative chemotherapy has proved to increase the time of progression-free survival [8]. In addition, adjuvant therapy after surgery alone confers a survival benefit [9-12]. Recently, the failure of patients to receive adjuvant chemotherapy due to poor performance status (PS) and complications after liver resection has been shown to have a negative impact on survival $[13,14]$. PS is a scoring system quantifying the impact of disease on a patient's well-being and is known as one of the strongest prognostic factors for survival in metastatic CRC 
patients $[15,16]$. The definitions of PS are shown in Table 1 [17]. The aim of the present study was to analyze factors associated with poor PS after resection for colorectal liver metastases and the impact on survival. In case of disease recurrence, the aim was to evaluate the PS of patients and to which extent patients received tumor specific treatment.

\section{Methods}

Medical records of all patients undergoing resection of colorectal liver metastases between 2010 and 2015 at a single center were reviewed. All patient data were retrieved retrospectively. Liver resection was performed as previously described [18]. A major resection was defined as resection of $\geq 3$ Couinaud's segments, and 30-day morbidity was classified according to Clavien-Dindo [19]. Postoperative poor PS was defined as a PS WHO $>2$. Adjuvant chemotherapy was defined as chemotherapy administered within 90 days after liver surgery. Indication for adjuvant therapy was considered when a R0 or R1 resection was performed and patients presented with a postoperative PS WHO 0-2. Synchronous disease was defined as when liver metastases were diagnosed during the radiological staging before resection of the primary. The overall and recurrence-free survival were recorded.

The study protocol was approved by the regional ethics committee.

\section{Statistical analysis}

Results were expressed as median and interquartile range. Mann-Whitney $U$ test was used to compare continuous data and $X^{2}$ test for categorical data. The Kaplan-Meier method was used to estimate the recurrence-free survival and overall survival. The log-rank test was used to compare the importance of postoperative PS. To analyze the effect of risk factors for adverse survival outcome, Cox regression analysis was used and hazard ratios with 95\% confidence intervals were calculated. Factors with a $P<0.1$

Table 1 Definitions of performance status

\begin{tabular}{|c|c|}
\hline Grade & WHO performance status \\
\hline 0 & $\begin{array}{l}\text { Fully active, able to carry on all pre-disease performance } \\
\text { without restriction }\end{array}$ \\
\hline 1 & $\begin{array}{l}\text { Restricted in physically strenuous activity but ambulatory } \\
\text { and able to carry out work of a light or sedentary nature, } \\
\text { e.g., light house work, office work }\end{array}$ \\
\hline 2 & $\begin{array}{l}\text { Ambulatory and capable of all self-care but unable to carry } \\
\text { out any work activities; up and about more than } 50 \% \text { of } \\
\text { waking hours }\end{array}$ \\
\hline 3 & $\begin{array}{l}\text { Capable of only limited self-care; confined to bed or chair } \\
\text { more than } 50 \% \text { of waking hours }\end{array}$ \\
\hline 4 & $\begin{array}{l}\text { Completely disabled; cannot carry on any self-care; totally } \\
\text { confined to bed or chair }\end{array}$ \\
\hline 5 & Dead \\
\hline
\end{tabular}

on univariable Cox regression analysis were included in the multivariable analysis. $P<0.05$ was considered statistically significant. Statistical analysis was performed using IBM SPSS Statistics version 22 (IBM, Armonk, NY, USA).

\section{Results}

A total of 284 patients were resected for colorectal liver metastases and form the study cohort. All patients had a postoperative consultation with an oncologist within 57 weeks after resection for PS evaluation and planning of adjuvant chemotherapy. All patients had PS WHO 0-2 before liver resection. Seventy-four patients (26\%) presented

Table 2 Patient characteristics for patients with postoperative WHO performance status $0-2$ vs. WHO performance status $>2$

\begin{tabular}{|c|c|c|c|}
\hline & $\begin{array}{l}\text { WHO performance } \\
\text { status, } 0-2 N=210\end{array}$ & $\begin{array}{l}\text { WHO performance } \\
\text { status, }>2 N=74\end{array}$ & $P$ value \\
\hline Male gender & 125 (59.5\%) & $51(68.9 \%)$ & 0.152 \\
\hline Age, years & $68(62-73)$ & $68(62-73)$ & 0.224 \\
\hline Smoking & $49(23.3 \%)$ & $10(13.5 \%)$ & 0.073 \\
\hline Diabetes mellitus & $22(10.5 \%)$ & $9(12.2 \%)$ & 0.689 \\
\hline $\begin{array}{l}\text { Body mass index } \\
\left(\mathrm{kg} / \mathrm{m}^{2}\right)\end{array}$ & $25(23-28)$ & $25(23-27)$ & 0.969 \\
\hline ASA grade $3-4$ & $53(25.2 \%)$ & $31(41.9 \%)$ & 0.007 \\
\hline $\begin{array}{l}\text { Preoperative } \\
\text { albumin }(\mathrm{g} / \mathrm{l})\end{array}$ & $38(35-40)$ & $38(35-40)$ & 0.452 \\
\hline $\begin{array}{l}\text { Preoperative } \\
\text { creatinine ( } \mu \mathrm{mol} / \mathrm{l})\end{array}$ & $73(63-83)$ & $80(66-95)$ & 0.052 \\
\hline Rectal primary & 71 (35.5\%) & $25(36.8 \%)$ & 0.851 \\
\hline Primary T4 & $45(24.7 \%)$ & $12(19.7 \%)$ & 0.420 \\
\hline Node positive primary & $116(63.7 \%)$ & $47(77.1 \%)$ & 0.056 \\
\hline Synchronous disease & $116(58.0 \%)$ & $30(44.1 \%)$ & 0.047 \\
\hline $\begin{array}{l}\text { Synchronous lung } \\
\text { and liver metastases }\end{array}$ & $11(5.7 \%)$ & $11(16.4 \%)$ & 0.006 \\
\hline$>1$ tumour & $125(60 \%)$ & 49 (66\%) & 0.353 \\
\hline Tumour size $>50 \mathrm{~mm}$ & $22(10.5 \%)$ & $8(10.8 \%)$ & 0.936 \\
\hline $\begin{array}{l}\text { Preoperative } \\
\text { chemotherapy }\end{array}$ & $123(58.6 \%)$ & $41(55.4 \%)$ & 0.635 \\
\hline $\begin{array}{l}\text { Preoperative } \\
\text { chemotherapy cycles }\end{array}$ & $5(4-6)$ & $4(3-5)$ & 0.600 \\
\hline $\begin{array}{l}\text { Preoperative } \\
\text { chemotherapy } \\
>6 \text { cycles }\end{array}$ & $16(7.7 \%)$ & $8(10.8 \%)$ & 0.416 \\
\hline $\begin{array}{l}\text { Operation time } \\
\text { (hours) }\end{array}$ & $5(3-6)$ & $5(3-7)$ & 0.251 \\
\hline $\begin{array}{l}\text { Operative } \\
\text { bleeding (ml) }\end{array}$ & $400(200-600)$ & $400(200-900)$ & 0.145 \\
\hline Major resection & $94(44.8 \%)$ & $33(44.6 \%)$ & 0.980 \\
\hline Hospital stay (days) & $7(6-8)$ & $7(6-10)$ & 0.214 \\
\hline $\begin{array}{l}\text { Morbidity } \\
\text { (Clavien-Dindo } \geq 3 \text { ) }\end{array}$ & $19(9.0 \%)$ & $16(21.6 \%)$ & 0.005 \\
\hline
\end{tabular}

Data are presented as number (percentage) or median (interquartile range) ASA American Society of Anesthesiologists 
with PS WHO $>2$ after surgery. These patients did not receive any adjuvant chemotherapy. The remaining 210 patients $(74 \%)$ received adjuvant chemotherapy, either as adjuvant treatment alone or as a complement to preoperative chemotherapy. Adjuvant chemotherapy was oxaliplatinbased $(n=152), 5$-fluorouracil alone $(n=36)$ or irinotecanbased $(n=15)$. Seven patients received a combination of two or more cytostatic regimens. Patients with adjuvant chemotherapy received a median of 7 (5-8) postoperative chemotherapy cycles.

The patient characteristics for the groups with postoperative PS WHO $0-2$ and $\mathrm{WHO}>2$ are shown in Table 2. No patient had tumor progression as reason for $\mathrm{PS} \mathrm{WHO}>2$. For patients with PS WHO 0-2 receiving adjuvant chemotherapy, treatment was initiated 50 (42-64) days after resection.

The median follow-up after liver resection was 33 months. During follow-up, 116 of 210 (55\%) patients developed recurrence of their disease in the group with postoperative PS WHO $0-2$. Ten patients (9\%) did not receive any tumor-specific treatment after relapse due to poor PS. Fifty-four of 74 (73\%) patients in the group with postoperative PS WHO $>2$ suffered from recurrence. In this group, 11 of 54 patients (20\%) did not receive tumor-specific treatment at recurrence due to poor PS ( $P=0.032$ as compared with the group WHO $0-2)$.

Kaplan-Meier estimates of recurrence-free and overall survival are shown in Figs. 1 and 2. The results of the Cox proportional hazard analysis of the adverse risk factors for survival outcome are shown in Table 3.

\section{Discussion}

In the present study, $26 \%$ of patients resected for colorectal liver metastases displayed a poor postoperative PS preventing administration of adjuvant chemotherapy. These patients had shorter overall and recurrence-free survival. In line with other studies [15], poor PS was the strongest independent factor for survival.

Patients with PS WHO $>2$ had higher ASA score as a measure of preoperative medical comorbidity and a more advanced disease with synchronous liver and lung metastases. This group of patients was also to a greater extent affected by major postoperative complications (Clavien-Dindo $\geq 3$ ). The reasons for change in PS are thus a combination of preoperative patient characteristics and postoperative adverse event. Because of poor PS, these patients did not receive oncological adjuvant chemotherapy. This finding is in line with previous studies reporting a failure to receive intended adjuvant chemotherapy of $13-37 \%$ of patients $[8,13,14]$. Postoperative morbidity has previously been shown to decrease the ability to tolerate adjuvant chemotherapy [13]. To enhance postoperative recovery, a fast-track protocol is used at our department since 2012, resulting in decreased length of stay but preliminary without impact on morbidity [18]. However, decreased morbidity after introduction of enhanced recovery protocols has been demonstrated [20]. In addition, laparoscopic liver resections are getting more widespread with the potential of lowering morbidity further $[13,21]$. The impact on these measures on postoperative PS and the ability to tolerate adjuvant chemotherapy is still to be investigated.

Adjuvant chemotherapy was initiated a median of 7 weeks after liver resection. After resection of colon cancer primary, evidence exists that adjuvant chemotherapy should be administrated within 8 weeks after surgery for best survival benefit [22]. There is however no data supporting that there is a similar window of

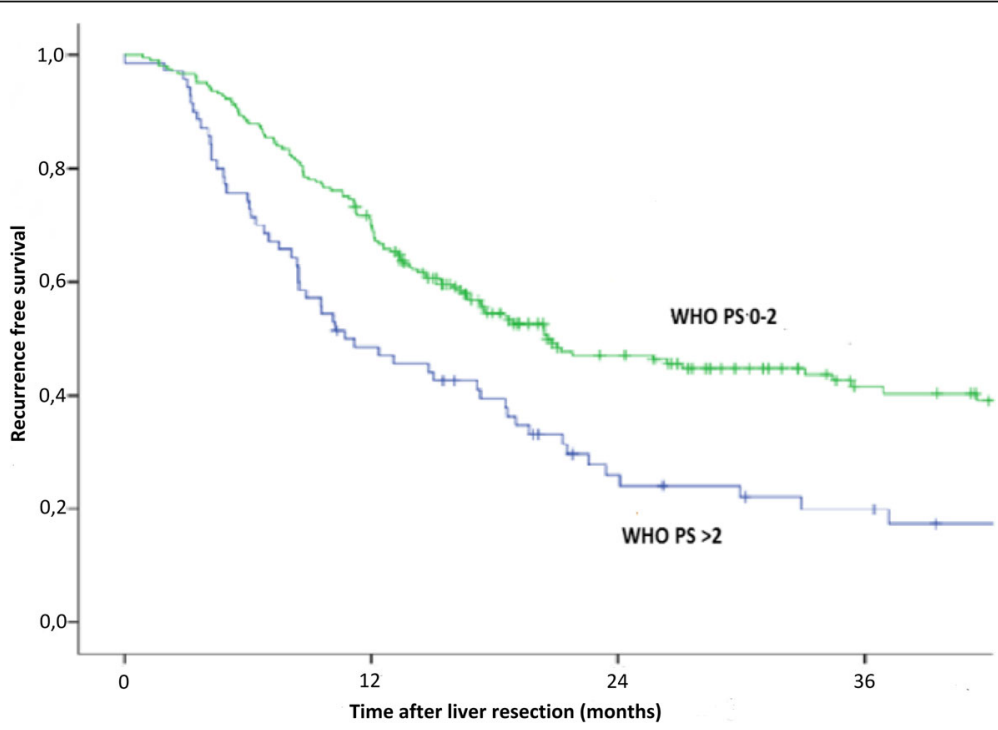

Fig. 1 Kaplan-Meier estimate of recurrence-free survival $(P=0.002$, log rank test). PS, performance status 


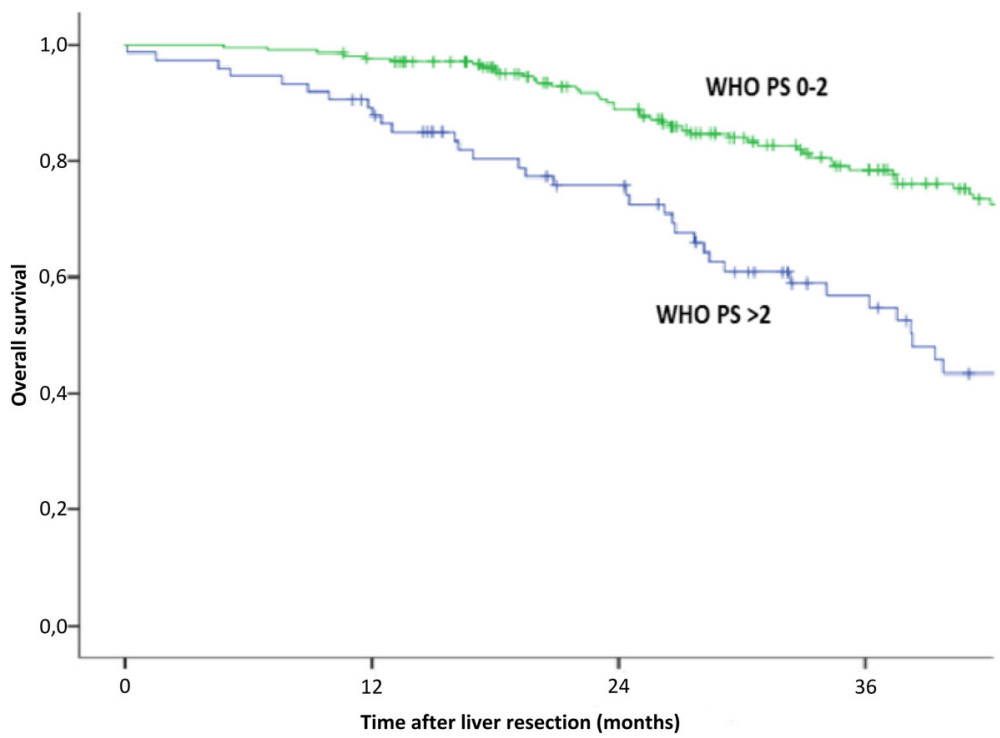

Fig. 2 Kaplan-Meier estimate of overall survival ( $P<0.001$, log rank test). PS, performance status

opportunity for starting adjuvant chemotherapy after liver resection. For a patient, in too poor general health to tolerate adjuvant chemotherapy on a postoperative consultation, the choice is between reassessing the patient after some time period and inhibiting adjuvant chemotherapy. No reassessment was done in the present study, much likely reflecting a general notion of an existing upper time limit for starting adjuvant chemotherapy extrapolated from treatment of primary colon cancer.
A significant number of patients in both WHO 0-1 and WHO $>2$ groups developed recurrent disease. A vast majority of patients in the WHO 0-2 group with recurrence was given tumor-specific treatment. In the WHO $>2$ group, 54 of 74 (73\%) patients developed recurrent disease. Also, in this group, most patients $(80 \%)$ received tumor specific treatment. These results also indicate that some of the patients who initially presented with poor PS after surgery, and therefore were not considered for

Table 3 Cox proportional hazard analysis of risk factors for adverse survival outcome

\begin{tabular}{|c|c|c|c|c|}
\hline \multirow[b]{2}{*}{ Variable } & \multicolumn{2}{|l|}{ Univariate } & \multicolumn{2}{|l|}{ Multivariate } \\
\hline & $\mathrm{HR}(95 \% \mathrm{Cl})$ & $P$ value & $\mathrm{HR}(95 \% \mathrm{Cl})$ & $P$ value \\
\hline Male gender & $1.38(0.91-2.10)$ & 0.125 & & \\
\hline Age & $1.00(0.98-1.0)$ & 0.816 & & \\
\hline Smoking & $1.02(0.63-1.67)$ & 0.931 & & \\
\hline Diabetes mellitus & $0.99(0.53-1.86)$ & 0.986 & & \\
\hline Body mass index & $0.99(0.94-1.05)$ & 0.841 & & \\
\hline ASA grade $3-4$ & $1.40(0.93-2.11)$ & 0.111 & & \\
\hline Rectal primary & $1.24(0.83-1.87)$ & 0.292 & & \\
\hline Primary T4 & $1.63(0.99-2.67)$ & 0.053 & $1.40(0.84-2.34)$ & 0.197 \\
\hline Node positive primary & $1.70(1.02-2.84)$ & 0.041 & $1.42(0.83-2.46)$ & 0.203 \\
\hline Synchronous disease & $1.62(1.08-2.45)$ & 0.021 & $1.77(1.05-2.96)$ & 0.031 \\
\hline Preoperative chemotherapy & $1.72(1.15-2.59)$ & 0.009 & $1.25(0.75-2.08)$ & 0.394 \\
\hline Preoperative chemotherapy $>6$ cycles & $1.57(0.86-2.88)$ & 0.142 & & \\
\hline Major resection & $1.16(0.78-1.71)$ & 0.461 & & \\
\hline Tumour size $>50 \mathrm{~mm}$ & $0.93(0.48-1.79)$ & 0.826 & & \\
\hline Morbidity (Clavien-Dindo $\geq 3$ ) & $1.68(1.0-2.83)$ & 0.051 & $1.38(0.70-2.70)$ & 0.352 \\
\hline WHO performance status, $0-2$ vs $>2$ & $0.45(0.30-0.68)$ & $<0.001$ & $0.52(0.32-0.86)$ & 0.010 \\
\hline
\end{tabular}


adjuvant chemotherapy, could possibly improve their PS by reducing postoperative complications. In addition, a later postoperative assessment of PS may potentially increase the number of patients who could tolerate postoperative adjuvant treatment. Further studies are necessary to investigate the optimal time window for adjuvant chemotherapy after surgery for colorectal liver metastases.

Although extensively used, the effective role of adjuvant chemotherapy is still controversial.

The present study showed that patients presenting with poor postoperative PS not receiving chemotherapy after liver resection had a shorter recurrence-free survival and a shorter overall survival. Previously reported in two randomized studies, adjuvant chemotherapy was associated with a trend to better survival $[9,10]$. The pooled data from both studies [11] support the assumption that adjuvant chemotherapy is associated with a longer progression-free survival as well as longer overall survival. Another large study [12] comparing resection of colorectal liver metastases with and without adjuvant chemotherapy showed that adjuvant chemotherapy prolongs postoperative survival. Liver resection and perioperative chemotherapy have been shown to result in a significant increase in disease-free survival when compared to surgery alone [8], although no difference in overall survival could be demonstrated [23].

Decreased recurrence-free survival and overall survival in patients with poor postoperative PS not receiving adjuvant chemotherapy in the present study could be due to patient selection. These patients had more medical comorbidity as well as more advanced disease in terms of synchronous lung metastases. In addition, no analysis of the influence of R0 or R1 status was made.

It is well known that PS is a strong prognostic factor for survival in patients with metastatic colorectal cancer [16]. There are also indications that patients with a good PS are the ones to benefit the most from adjuvant chemotherapy after resection of colorectal metastases [24]. Postoperative complications after resection of colorectal liver metastases have been associated with poor overall and recurrencefree survival, as well as delayed initiation of chemotherapy [14]. It seems therefore crucial to reduce postoperative complications, which possibly could be achieved by introducing enhanced recovery programs and shifting into more mini-invasive surgical techniques.

\section{Conclusions}

The present study showed that a significant number of patients undergoing liver resection for colorectal liver metastases did not recover in time for the intended adjuvant chemotherapy. These patients had shorter overall and recurrence-free survival. However, a great majority of patients that presented with poor PS after surgery received palliative chemotherapy or other surgical treatment after disease recurrence.
Abbreviations

ASA: American Society of Anesthesiologists; CRC: Colorectal cancer; PS: Performance status

\section{Acknowledgements}

Not applicable

\section{Funding}

This work was supported by the Erik och Angelica Sparres research foundation.

\section{Availability of data and materials}

Data supporting our findings can be accessed upon request to the corresponding author.

\section{Authors' contributions}

$\mathrm{PSH}, \mathrm{GL}, \mathrm{SE}, \mathrm{JE}, \mathrm{MB}$, and CS were all active in the design of the study. PSH, $\mathrm{SE}$, and $\mathrm{CS}$ analyzed the data. PSH and CS wrote the manuscript. PSH, SE, JE, $M B, G L$, and $C S$ reviewed the manuscript and approved the final manuscript.

Ethics approval and consent to participate

The study protocol was approved by the regional ethics committee.

\section{Consent for publication}

Not applicable

\section{Competing interests}

The authors declare that they have no competing interests.

\section{Publisher's Note}

Springer Nature remains neutral with regard to jurisdictional claims in published maps and institutional affiliations.

\section{Author details}

'Department of Clinical Sciences Lund, Surgery, Skane University Hospital, Lund University, Lund, Sweden. ${ }^{2}$ Department of Clinical Sciences Lund, Oncology, Skane University Hospital, Lund University, Lund, Sweden. ${ }^{3}$ Department of Surgery, Skåne University Hospital, S-221 85 Lund, Sweden.

Received: 27 August 2017 Accepted: 26 December 2017

Published online: 05 January 2018

References

1. Adam R, De Gramont A, Figueras J, Guthrie A, Kokudo N, Kunstlinger F, Loyer E, Poston G, Rougier P, Rubbia-Brandt L, et al. The oncosurgery approach to managing liver metastases from colorectal cancer: a multidisciplinary international consensus. Oncologist. 2012;17:1225-39.

2. Scheele J, Stang R, Altendorf-Hofmann A, Paul M. Resection of colorectal liver metastases. World J Surg. 1995;19:59-71.

3. Kanas GP, Taylor A, Primrose JN, Langeberg WJ, Kelsh MA, Mowat FS, Alexander DD, Choti MA, Poston G. Survival after liver resection in metastatic colorectal cancer: review and meta-analysis of prognostic factors. Clin Epidemiol. 2012;4:283-301.

4. Veereman G, Robays J, Verleye L, Leroy R, Rolfo C, Van Cutsem E, Bielen D, Ceelen W, Danse E, De Man M, et al. Pooled analysis of the surgical treatment for colorectal cancer liver metastases. Crit Rev Oncol Hematol. 2015;94:122-35.

5. Gallagher DJ, Kemeny N. Metastatic colorectal cancer: from improved survival to potential cure. Oncology. 2010;78:237-48.

6. D'Angelica M, Kornprat $\mathrm{P}$, Gonen M, DeMatteo RP, Fong $Y$, Blumgart LH, Jarnagin WR. Effect on outcome of recurrence patterns after hepatectomy for colorectal metastases. Ann Surg Oncol. 2011;18:1096-103.

7. Jones RP, Malik HZ, Fenwick SW, Poston GJ. Perioperative chemotherapy for resectable colorectal liver metastases: where now? Eur J Surg Oncol. 2013;39:807-11.

8. Nordlinger B, Sorbye H, Glimelius B, Poston GJ, Schlag PM, Rougier P, Bechstein WO, Primrose JN, Walpole ET, Finch-Jones M, et al. Perioperative chemotherapy with FOLFOX4 and surgery versus surgery alone for resectable liver metastases from colorectal cancer (EORTC Intergroup trial 40983): a randomised controlled trial. Lancet. 2008;371:1007-16.

9. Portier G, Elias D, Bouche O, Rougier P, Bosset JF, Saric J, Belghiti J, Piedbois P, Guimbaud R, Nordlinger B, et al. Multicenter randomized trial of adjuvant 
fluorouracil and folinic acid compared with surgery alone after resection of colorectal liver metastases: FFCD ACHBTH AURC 9002 trial. J Clin Oncol. 2006;24:4976-82.

10. Langer B, Bleiberg H, Labianca R, et al. Fluorouracil (FU) plus I-leucovorin (I-LV) versus observation after potentially curative resection of liver or lung metastases from colorectal cancer (CRC): results of the ENG (EORTC/NCIC) CTG/GIVIO) randomized trial. Proc Am Soc Clin Oncol. 2002;21:149a.

11. Mitry E, Fields AL, Bleiberg H, Labianca R, Portier G, Tu D, Nitti D, Torri V, Elias D, O'Callaghan C, et al. Adjuvant chemotherapy after potentially curative resection of metastases from colorectal cancer: a pooled analysis of two randomized trials. J Clin Oncol. 2008:26:4906-11.

12. Parks R, Gonen M, Kemeny N, Jarnagin W, D'Angelica M, DeMatteo R, Garden OJ, Blumgart LH, Fong Y. Adjuvant chemotherapy improves survival after resection of hepatic colorectal metastases: analysis of data from two continents. J Am Coll Surg. 2007:204:753-61. discussion 761-753

13. Aloia TA, Zimmitti G, Conrad C, Gottumukalla V, Kopetz S, Vauthey JN. Return to intended oncologic treatment (RIOT): a novel metric for evaluating the quality of oncosurgical therapy for malignancy. I Surg Oncol. 2014;110:107-14.

14. Correa-Gallego C, Gonen M, Fischer M, Grant F, Kemeny NE, Arslan-Carlon V, Kingham TP, Dematteo RP, Fong Y, Allen PJ, et al. Perioperative complications influence recurrence and survival after resection of hepatic colorectal metastases. Ann Surg Oncol. 2013;20:2477-84.

15. Sorbye H, Kohne CH, Sargent DJ, Glimelius B. Patient characteristics and stratification in medical treatment studies for metastatic colorectal cancer: a proposal for standardization of patient characteristic reporting and stratification. Ann Oncol. 2007;18:1666-72.

16. Stillwell AP, Ho YH, Veitch C. Systematic review of prognostic factors related to overall survival in patients with stage IV colorectal cancer and unresectable metastases. World J Surg. 2011;35:684-92.

17. Oken MM, Creech RH, Tormey DC, Horton J, Davis TE, McFadden ET, Carbone PP. Toxicity and response criteria of the Eastern Cooperative Oncology Group. Am J Clin Oncol. 1982;5:649-55.

18. Blind PJ, Andersson B, Tingstedt B, Bergenfeldt M, Andersson R, Lindell G, Sturesson C. Fast-track program for liver resection-factors prolonging length of stay. Hepato-Gastroenterology. 2014;61:2340-4.

19. Dindo D, Demartines N, Clavien PA. Classification of surgical complications: a new proposal with evaluation in a cohort of 6336 patients and results of a survey. Ann Surg. 2004;240:205-13.

20. Hughes MJ, McNally S, Wigmore SJ. Enhanced recovery following liver surgery: a systematic review and meta-analysis. HPB (Oxford). 2014;16:699-706.

21. Alkhalili E, Berber E. Laparoscopic liver resection for malignancy: a review of the literature. World J Gastroenterol. 2014;20:13599-606.

22. Chau I, Cunningham D. Adjuvant therapy in colon cancer-what, when and how? Ann Oncol. 2006;17:1347-59.

23. Nordlinger B, Sorbye H, Glimelius B, Poston GJ, Schlag PM, Rougier P, Bechstein WO, Primrose JN, Walpole ET, Finch-Jones M, et al. Perioperative FOLFOX4 chemotherapy and surgery versus surgery alone for resectable liver metastases from colorectal cancer (EORTC 40983): long-term results of a randomised, controlled, phase 3 trial. Lancet Oncol. 2013:14:1208-15.

24. Sorbye H, Mauer M, Gruenberger T, Glimelius B, Poston GJ, Schlag PM, Rougier P, Bechstein WO, Primrose JN, Walpole ET, et al. Predictive factors for the benefit of perioperative FOLFOX for resectable liver metastasis in colorectal cancer patients (EORTC Intergroup trial 40983). Ann Surg. 2012:255:534-9.

\section{Submit your next manuscript to BioMed Central and we will help you at every step:}

- We accept pre-submission inquiries

- Our selector tool helps you to find the most relevant journal

- We provide round the clock customer support

- Convenient online submission

- Thorough peer review

- Inclusion in PubMed and all major indexing services

- Maximum visibility for your research

Submit your manuscript at www.biomedcentral.com/submit
) Biomed Central 